\title{
Heat Extraction Distributed Thermal Response Test: a methodological approach and in-situ experiment
}

\section{Davide Rolando}

\author{
José Acuña
}

Marco Fossa

\begin{abstract}
The Thermal Response Test (TRT) is a worldwide adopted in-situ methodology able to estimate the ground thermal conductivity and borehole thermal resistance. During the test the carrier-fluid exchanges a constant heat flux with the ground while circulating in a pilot Borehole Heat Exchanger (BHE). During a Distributed Thermal Response Test (DTRT) the ground thermal conductivity and borehole thermal resistance are determined at different vertical sections along the borehole.

The measured fluid temperature values are analysed with numerical or analytical approaches based on mathematical models which typically approximate the BHE. Those models are based on some strict assumptions, including pure conduction and constant heat transfer rate.

During a heat extraction TRT the operating conditions to the ground are similar to the "winter mode" conditions of a working BHE system. In such case the estimated thermal behaviour of the borehole can differ from the result obtained by means of a heat injection TRT. This issue is of peculiar interest for water-filled boreholes, where the BHE thermal resistance is related to the water temperature and density gradient in the borehole filling-space. In this operating mode a heat pump is usually employed and the constant heat transfer rate condition required by the models can be difficult to be respected since the efficiency of the cooling-machine is dependent on the inlet carrier-fluid temperature to the evaporator.

In this paper a methodology to perform a heat extraction DTRT with constant heat transfer rate to the ground is presented. The approach described has been applied in a real water-filled borehole installed in Stockholm, Sweden. Data analysis results are presented and the outcomes regarding the evaluation of the local borehole thermal resistance are discussed and compared with those from an erlier heat injection test performed in the same borehole.
\end{abstract}

\section{INTRODUCTION}

Over 1.7 million Heat Pump units have been sold in the European Union in 2014, for an estimated energy production of about $13 \mathrm{TWh}$. In Sweden, where the largest share for ground source units have been sold, the employment of ground-water filled boreholes is the most common solution (Eurobserv'er 2015).

An accurate borehole system design involves the challenge of properly estimating the the thermal properties of both ground and heat exchangers. The undisturbed ground temperature $\left(T_{g r, \infty}\right)$, the ground thermal conductivity $\left(k_{g r}\right)$ and the borehole thermal resistance $\left(R_{b}\right)$ need to be measured or estimated with sufficient accuracy, since they have a direct impact on the efficiency and operation costs of heat pump systems (Marcotte and Pasquier 2008). The total number of heat exchangers and the overall borehole length strongly affect the general system cost. Hence, the correct sizing of the borefield, through a preliminary investigation on the ground properties, is a compulsory task in order to obtain shorter payback periods.

The thermal response test is well known technique for evaluating the ground conductivity and the borehole thermal resistance. Since modern TRT apparatus started to be developed (Austin 1998, Eklöf and Gehlin 1996), the TRT experimental method has been applied successfully with different approaches and settings (Spitler and Gehlin

Davide Rolando is post-doctoral researcher at KTH Energy Technology Department (davide.rolando@energy.kth.se), Stockholm, Sweden. José Acuna is researcher at KTH Energy Technology Department, Stockholm, Sweden and Marco Fossa is professor of Solar and Geothermal Energy at University of Genova, Italy. 
2015). The most widely used analysis method is based on the response of an Infinite Line Source model (ILS) (Carslaw and Jaeger 1945, Ingersoll and Plass 1948, de Vries 1952, Mogensen 1983) or an Infinite Cylindrical Source model (ICS), since those are the easiest to be implemented (Gehlin et al. 2003).

The test methodology has a number of important limitations given mainly by the analysis method assumptions and by practical experimental issues. The thermal energy rate is assumed to be constant during the test and the uncontrolled variation of the heat flux to the borehole circulating fluid affects the results. Beier and Smith (2003) propose a deconvolution algorithm to remove the variable heat rate effect from test. An analysis procedure based on the superposition principle of the basic analytical model solution can also be employed when measured data are affected by variable heat rate. On the other hand, modern apparatus, as described for example in Witte et al. (2002) and Rolando (2015), allow to maintain the heat transfer constant during the test by employing a feedback control system. The ground thermal properties are assumed to be homogenous even if usually the geological profile along the borehole heat exchanger includes layers with different characteristics. The undisturbed ground temperature is also considered to be completely homogeneous and the real temperature is not considered. Numerical simulations and analysis have demonstrated that the undisturbed ground temperature gradient can affect the estimation of the ground thermal properties (Signorelli 2004). Fujii et al. (2006) defined a new methodological approach consisting in the measurement of the temperature along the borehole by means of optical fiber cables installed on the external wall of the pipes. This methodology is nowadays known as named Distributed Thermal Response Test (DTRT). Following the same approach, Acuña et al. (2009) introduced the possibility to evaluate the complete borehole thermal resistance by locating the optical fiber inside the pipes. Witte (2005) presented a test protocol based on the application of several energy pulses including heat injection and heat extraction. Witte (2013) provides and extensive discussion on the uncertainty analysis related to TRT parameter estimation. A similar test protocol has also been tested in groundwater-filled BHEs yelding a good result in detecting thermally induced convective flow in the borehole water (Gustafsson 2011).

Despite heat injection is the most common test mode for TRT, heat extraction tests allow to investigate the ground and borehole thermal properties in temperature ranges comparable to the actual temperature range of heat pump systems used for space heating (Witte and van Gelder 2006). In ground-water filled heat exchangers the convection around the borehole affects the results and the borehole thermal resistance will vary more than heat injection tests. Water has the highest density around $4^{\circ} \mathrm{C}$ and the convective flow is affected by the ground water-fill temperature across this value. If the temperature in the groundwater falls below zero latent heat is also released during the phase change and the heat transfer properties change as ice is formed. Due to the complexity of the heat transfer phenomena, with the available TRT analysis methods involving line source and parameter estimation based on a conductive heat transfer model, the adoption of one $R_{b}$ value for heat extraction TRT in groundwater-filled BHEs is not possible (Gustafsson 2011).

As well known, the main issue related to performing a Heat Extraction TRT (HETRT) is due to the chiller (heat pump) performance dependence on the evaporation temperature. This implies that the heat transfer rate extracted from the ground cannot be constant without the employment of a dedicated control. In this paper the description of the experimental methodology adopted for performing a heat extraction test maintaining the heat transfer rate constant is presented including the results from a field experiment where the temperatures along the borehole have been measured allowing the estimation of the borehole thermal resistance at a local level. The estimated values are presented and discussed focusing on the comparison of the results to the values obtained in the same borehole during a heating TRT. 


\section{DISTRIBUTED HEAT EXTRACTION THERMAL RESPONSE TEST}

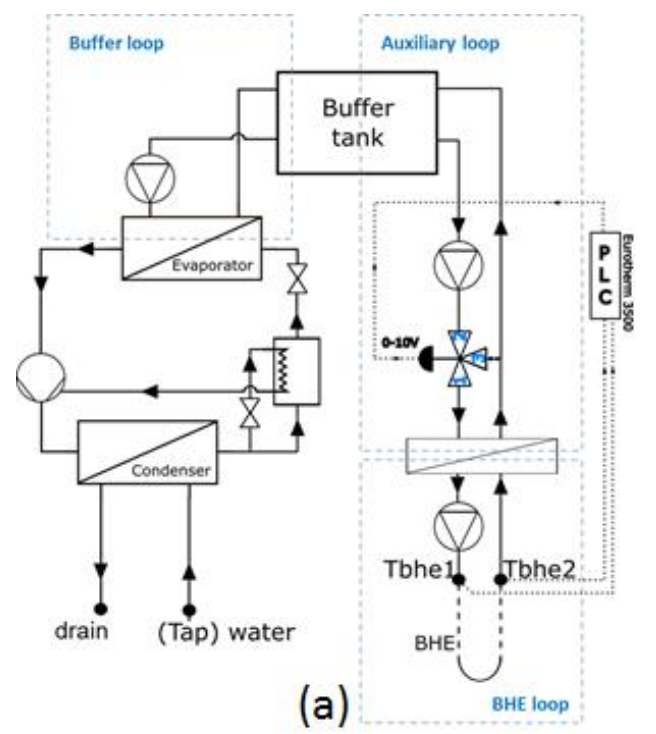

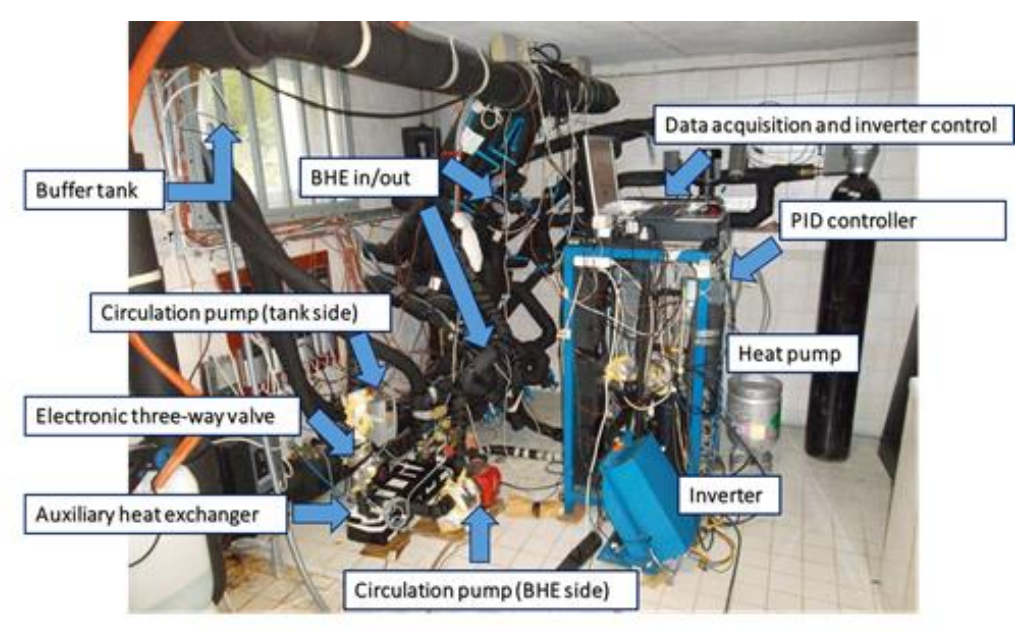

(b)

Figure 1 Heat Extraction TRT: (a) test layout and (b) field experiment.

In Northern Europe countries like Sweden and Norway, the filling material commonly used in Borehole Heat Exchangers is the ground water. In such systems, the effect of the convection induced by the temperature and density gradients of the ground surrounding the borehole may not be neglectable. During a heat injection TRT the thermal behaviour of a BHE, usually described by the effective thermal resistance (Mogensen 1983, Javed and Spitler 2016), can be very different when compared to a heat extraction TRT. Furthermore, in northern coutries a BHE system is mainly used in heat extraction mode. For these reasons, a Heat Extraction TRT (HETRT) allows to better characterize a BHE in an operating mode closer to the real working conditions of a ground source heat pump system.

A field experiment has been carried out aiming to perform a HETRT maintaining constant the heat extracted from the ground. The BHE has been described in Section 3.2.1 of the Acuña's (2013) Doctoral Thesis. It consists in 6 ground-water filled boreholes positioned in an $\mathrm{L}$ shaped arrangement. Two of these BHEs are U-pipe polyethylene heat exchangers and have been installed together with an optical fiber cable both inside and outside the pipes. The optical fiber cable is installed along the borehole pipes and extended also to the ground-water between the pipes and the borehole wall. By means of a Distributed Temperature Sensing (DTS) device, laser light pulses are sent through the optical fiber. The signal is refracted back from each section of the fiber cable and is sent back to the laser instrument with a frequency scattering (Raman scattering), that depends on the local temperature (Acuña 2013). The depth of the borehole used for this experiment is $260 \mathrm{~m}$. Worth noticing, the BHE used in the field experiment described in the following is part of a working system and it was rested for more than two months before the test has been carried out.

Figure 1a shows the layout of the field experiment. The main components of the test rig are: a water to water heat pump unit, a buffer tank, an auxiliary plate heat exchanger, an electronic three-way valve, a PID controller and three circulation pumps. The main idea was to control and maintain constant the borehole inlet and outlet temperature difference in order to keep constant the extracted heat transfer rate. The flow rate into the borehole was assumed to be constant and it has been verified during the data analysis.

The condenser inlet of the heat pump has been connected to the tap water while the outlet was connected to the drain. The evaporator has been connected to the buffer tank through a dedicated piping loop including a circulation pump. An auxiliary piping loop has been provided to connect the buffer tank to an auxiliary plate heat exchanger. In 
this loop, an electronic three-way valve was set to modulate the flow rate in one side of the plate heat exchanger. Finally, the other side of the auxiliary heat exchanger has been connected to the borehole.

A Proportional Integrative (PI) controller has been tuned in order to control the opening of the three-way valve and maintain the difference between the inlet and outlet borehole temperatures constant. The set point temperature of the storage tank was $-10^{\circ} \mathrm{C}$. The heat pump employed was a variable capacity unit and the compressor speed was controlled by means of an inverter. A computer code has been developed to control the heat pump compressor speed through the inverter during the test. A web interface has also been developed to monitor and control the experiment remotely.

Figure $1 \mathrm{~b}$ shows the complete equipment assembled in the field. All the pipes and heat exchangers have been properly insulated in order to minimize the heat loss during the experiment. A water and ethanol solution has been properly prepared in order to cope with the expected evaporator working temperature. Since the expected evaporation temperature was between -15 and $-18{ }^{\circ} \mathrm{C}$ (depending on the compressor speed), the buffer tank was filled with an aqueous solution of ethanol (about $35 \%$ by weight) in order to have a freezing temperature of about $-22^{\circ} \mathrm{C}$. The ethanol concentration in the borehole loop was about $16 \%$ by weight and it has not been modified.

\section{Data analysis}

The optical fiber measurements have been collected by a DTS device having a space resolution of $2 \mathrm{~m}$. As explained in the following section, before the constant extraction rate methodology presented above could be employed, the measurement campaign included a number of heat extraction and recovery cycles with different heat extraction rates. In order to analyse the data considering the variable heat rate, the superposition principle has been applied to the solution of the ILS model for each heat pulse considered. For each section, the borehole wall temperature $T_{b}$ has been calculated through the expression given by Eq. 1 .

$T_{b}-\mathrm{T}_{g r, \infty}=\sum_{i=1}^{n}\left(\dot{Q}^{\prime}{ }_{i}-\dot{Q}^{\prime}{ }_{i-1}\right) \frac{\mathrm{E}_{i}\left(\mathrm{Fo}\left(\tau_{n}-\tau_{i}\right)\right)}{\pi k_{g r}}$

Where $\mathrm{T}_{g r, \infty}$ is the undisturbed ground temperature, $\dot{Q}^{\prime}$ is the heat transfer rate per unit length, $\dot{Q}^{\prime}{ }_{i}-\dot{Q}^{\prime}{ }_{i-1}$ represents the heat heat transfer rate pertaining to the $i^{\text {th }}$ heat pulse and related to a given section, $\mathrm{n}$ is the number of heat pulses considered, $\mathrm{k}_{g r}$ is the ground thermal conductivity, Fo is the Fourier number based on the borehole radius and $\tau$.is the time. $\mathrm{E}_{i}$ is the Infinite Line Source model response factor (Ingersoll 1948). The approximation suggested by Abramowitz and Stegun (1964) has been adopted to evaluate the $E_{i}$ values without involving numerical integration, as it is shown in Eq.2.

$$
E_{i}=-\gamma-c_{1} \ln (X)-\sum_{j=2}^{5} c_{j} X^{j}
$$

Where $\gamma \approx 0.5772$ is the Euler constant $\mathrm{X}=1 /(4 F o)$ and $c_{j}$ are constant coefficients: $\mathrm{c}_{1}=0.99999193, \mathrm{c}_{2}=-$ $0.24991055, \mathrm{c}_{3}=0.05519968, \mathrm{c}_{4}=-0.00976004, \mathrm{c}_{5}=0.00107857$.

For each section, the local borehole thermal resistance has been calculated at each time step by means of Eq.3.

$$
R_{b}=\frac{\bar{T}_{f}-T_{b}}{\dot{Q}^{\prime}}
$$

Where $\bar{T}_{f}$ is the average temperature of the fluid circulating in the section.

For a generic section between the depths $A$ and $B$, the heat transfer rate is calculated at each time step considering the inlet and outlet fluid temperatures of both downward and upward pipes, as it is shown in Eq.4.

$$
\dot{Q}=\dot{m} c\left(\left(T_{\text {down, }}-T_{\text {down }, \mathrm{A}}\right)+\left(T_{\text {up, } \mathrm{A}}-T_{\text {up, } \mathrm{B}}\right)\right)
$$

Where, $\dot{m}$ is the fluid mass flow rate, $\mathrm{T}_{\text {down }}$ and $\mathrm{T}_{\text {up }}$ are the fluid temperatures measured in the downward and 
upward pipe, respectively. The fluid specific heat, $c$, has been assumed constant and equal to $4.372 \mathrm{~kJ} /(\mathrm{kg} \mathrm{K})$.

\section{RESULTS}

An overall test of $440 \mathrm{~h}$ has been carried out and Figure 2 shows the average fluid temperature evolution related to the 12 sections considered along the borehole. For each section the temperatures are measured inside both downward and upward pipes and the average of all the values is calculated at each time.

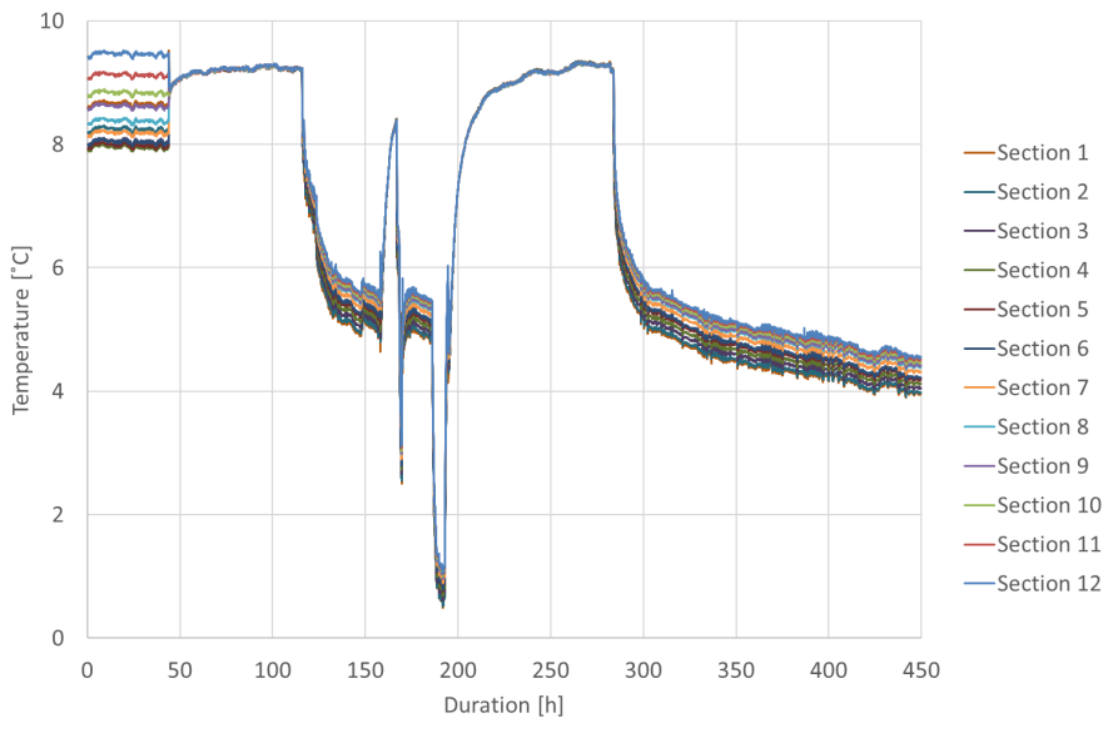

Figure 2 Optical fiber temperature measurements: BHE section temperatures over the entire $450 \mathrm{~h}$ test.

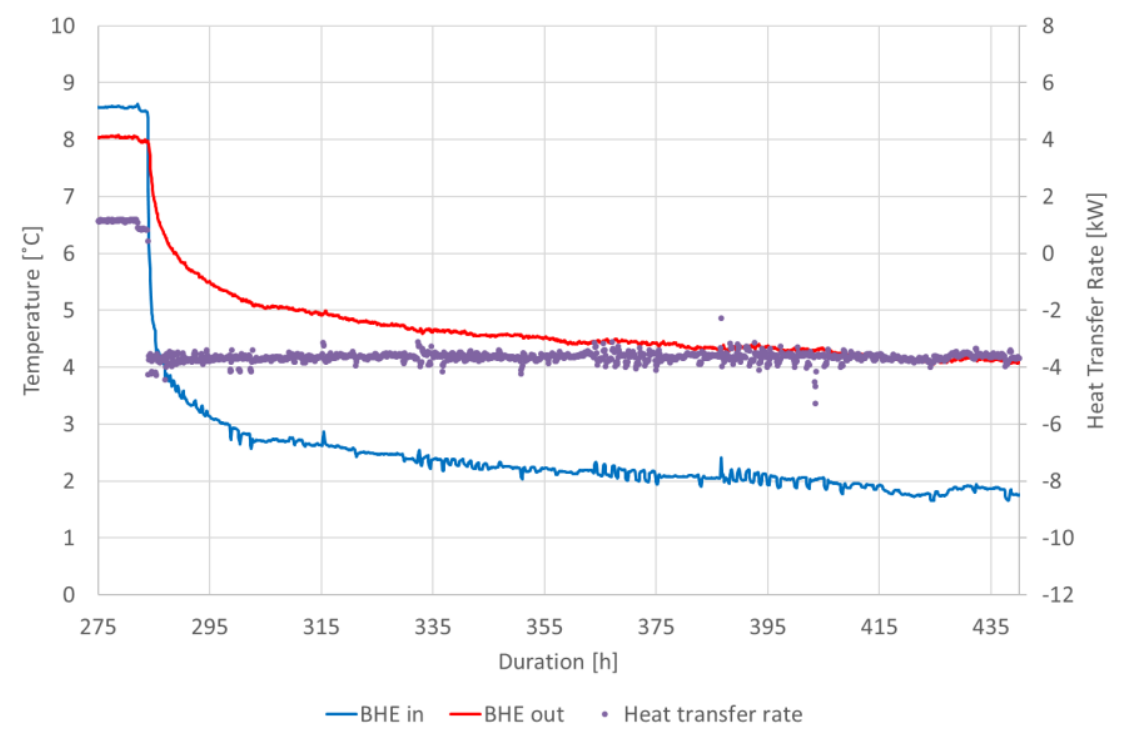

Figure 3 Constant heat transfer rate results from the employment of the presented experimental methodology. 
The sample time of the measurements was 5 minutes. Several heat extraction and recovery cycles have been carried out before the methodology described in the previous section could actually be applied in order to perform a final test maintaining constant the heat transfer rate. From the inspection of the figure, during a first stage of approximately $48 \mathrm{~h}$ the undisturbed ground temperature has been recorded for every sections. After that, for a period of about $70 \mathrm{~h}$ the fluid has been circulated in the borehole. A series of interrupted heat extraction tests can be observed between $120 \mathrm{~h}$ and $190 \mathrm{~h}$, due to the failure of the TRT control system to which the test rig had been connected to. At $190 \mathrm{~h}$ a temperature drop has been caused by the temporary change of the TRT layout that has been required to solve the control system issue. In the time windows between $285 \mathrm{~h}$ and $440 \mathrm{~h}$, the constant heat transfer rate DTRT has been finally carried out.

Figure 3 shows the borehole inlet and outlet temperature evolution during the final test and the evolution of the calculated heat transfer rate. As can be observed, the active control technique presented in this paper proved to be able to maintain constant the heat extracted from the ground with a good stability.

\section{Comparison to heating DTRT}

Based on the last 150 hours of the test presented above, local borehole resistance values have been calculated. The same equipment and a similar methodology as used in Acuña et al. (2009) has been followed, i.e. the same borehole, the same borehole heat exchanger, the circulating fluid and same measurement equipment. The local rock thermal conductivity values found during heat injection tests have also been adopted for the present data analysis. The thermal conductivity range is between 2.60 and $3.62 \mathrm{~W} / \mathrm{mK}$ in 12 different borehole sections, with an average of $3.10 \mathrm{~W} / \mathrm{mK}$. The results are shown in Figure 4.
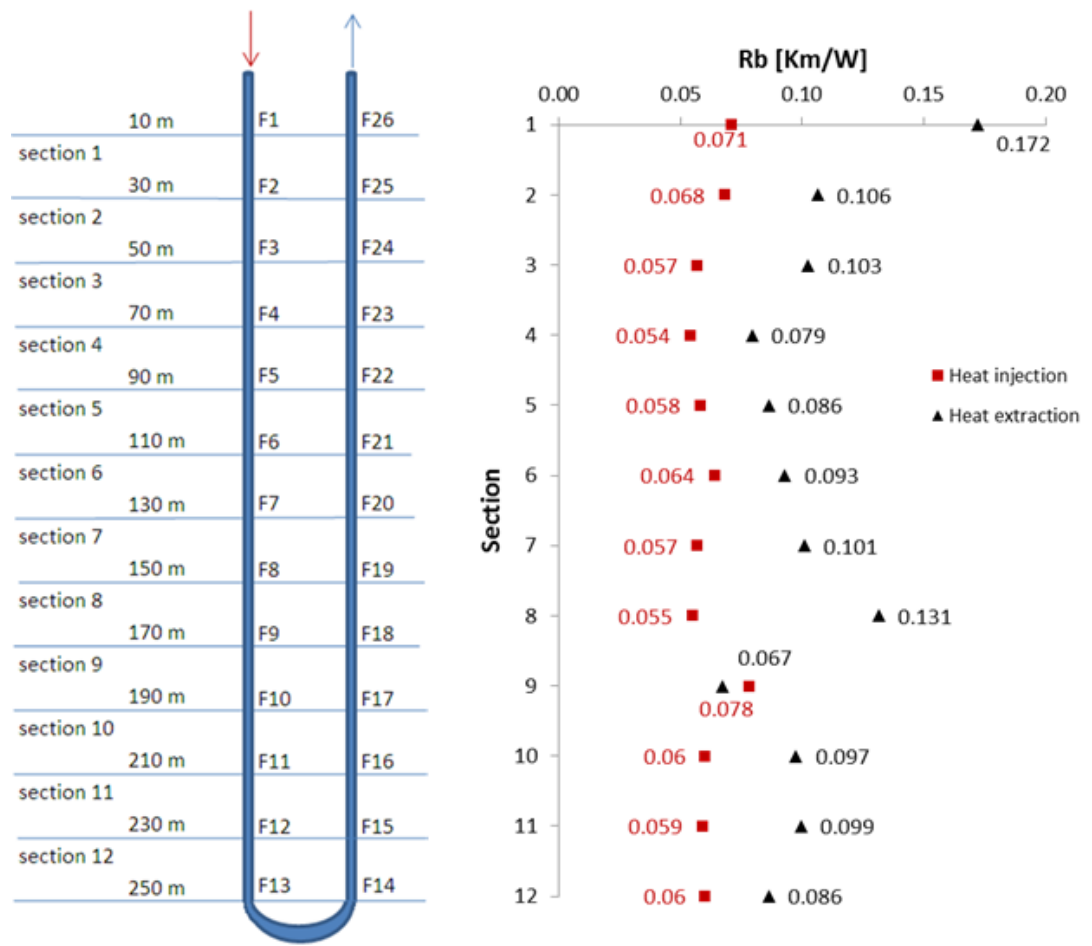

Figure 4 Comparison of measured local borehole resistances during heat injection and extraction DTRTs

The volumetric flow rates were different in the two tests, i.e. $0.36 \mathrm{l} / \mathrm{s}$ and $0.53 \mathrm{l} / \mathrm{s}$ in the heat extraction and 
injection test, respectively. Due to difference in flow and fluid temperature, a difference in the fluid to pipe thermal resistance of about $0.0087 \mathrm{mK} / \mathrm{W}$ (0.016 during cooling and $0.0073 \mathrm{mK} / \mathrm{W}$ during heating) is expected during these two tests. Heat extraction and injection tests were carried out at temperatures of about 5 and $15^{\circ} \mathrm{C}$, respectively.

The average local borehole resistance obtained during heat extraction was $0.102 \mathrm{mK} / \mathrm{W}$ and ranged from 0.067 to $0.172 \mathrm{mK} / \mathrm{W}$. The lowest value, in section 9, is presumably affected by a local borehole anomaly. It is known from Acuña (2013) that a borehole anomaly exists in the vicinity of $190 \mathrm{~m}$ depth, which may be the cause of the differences observed. Discontinuities in this section of the borehole have also been noticed during other tests in this borehole. The description and discussion related to this observed anomaly can be found in Section 3.3 (page 42) of Acuña's (2013) Doctoral Thesis as well as in Section 2.1 of Acuña's (2010) Licentiate thesis.

During the heat injection test, the average local borehole resistance was equal to $0.063 \mathrm{mK} / \mathrm{W}$ and ranged between 0.054 to $0.078 \mathrm{mK} / \mathrm{W}$.

The average difference between the heat extraction and the heat injection test is $0.039 \mathrm{mK} / \mathrm{W}$.

While observing differences between these two tests, it is important to keep in mind that the error of the measurements from the heat injection test range between 13\% and 17\%, as described in Acuña (2013). Since the same thermal conductivity values were used as an input to the calculations in the heat extraction test, a similar error level is expected.

Another aspect to be kept in mind while comparing these values is the extracted cooling power of about 3.6kW, compared to $9 \mathrm{~kW}$ while injecting power. Given the low power used in the heat extraction test, small radial temperature gradients between the pipes and the borehole wall can be expected in spite of the variation in borehole resistance.

Local borehole resistances resulted to be larger during heat extraction periods. Although this was expected given the lower temperature levels and the employment of a water-filled borehole, it can be of particular interest to go further and observe tendencies along the borehole depth. The difference in borehole resistance influenced by the groundwater temperatures is somewhat already forecasted. Current ongoing work is being dedicated to the temperature dependency of the local resistance values, as referred to groundwater temperatures inside the boreholes. This investigation will be put in perspective with earlier work carried out in Gustafsson (2010) and Spitler et al. (2016), among others.

\section{CONCLUSIONS AND FUTURE WORKS}

In this paper a methodology to perform a heat extraction DTRT maintaining constant the extraction rate has been presented and a field experimental set up has been described. The methodology proved to allow to maintain a constant heat rate extracted from the ground with a good stability.

The field measurements have been used to estimate the local values of the borehole thermal resistance in 12 sections considered along the borehole. The results have been compared and discussed with those from a previous heat injection test. Assuming that the local ground thermal conductivities are the same as found during the earlier heat injection test, the local borehole thermal reistances during the heat extraction DTRT are about $40 \%$ higher compared to the heat injection DTRT.

Future work is addressed to further analysis of the measurements including the investigation of the borehole thermal resistance values versus the water-fill temperature along the borehole.

\section{NOMENCLATURE}

$$
\begin{aligned}
F_{0} & =\text { Fourier number, } \mathrm{FO}_{\mathrm{O}}=(\alpha \tau) / r_{b}{ }^{2} \\
k & =\text { Thermal conductivity }(\mathrm{W} / \mathrm{mK}) \\
\dot{Q} & =\text { Heat transfer rate }(\mathrm{W}) \\
\dot{Q}^{\prime} & =\text { Heat transfer rate per unit length }(\mathrm{W} / \mathrm{m}) \\
r_{b} & =\text { Borehole radius }(\mathrm{m})
\end{aligned}
$$




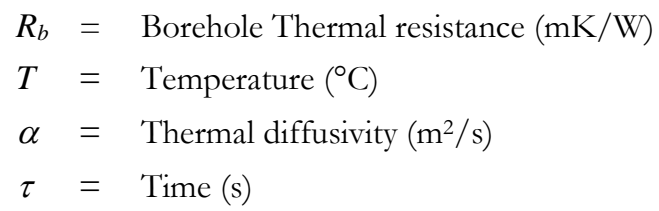

\section{Subscripts}

$\begin{aligned} f & =\text { carrier fluid } \\ b & =\text { borehole } \\ g r & =\text { ground } \\ \infty & =\text { undisturbed conditions }\end{aligned}$

\section{REFERENCES}

Abramowitz M. and I. A. Stegun. 1964. Handbook of mathematical functions: with formulas, graphs, and mathematical tables. Volume 55. Courier Corporation.

Acuña J, Mogensen P, Palm B. 2009. Distributed Thermal Response Test on a U-Pipe Borehole Heat Exchanger. The 11th International Conference on Energy Storage, Stockholm.

Acuña J. 2010. Improvements of U-pipe Borehole Heat Exchangers. KTH Royal Institute of Technology, Energiteknik,. Licentiate thesis. http:// wmw.diva-portal.org/smash/get/diva2:318637/FULLTEXT01.pdf

Acuña J. 2013. Distributed Thermal Response Tests: New insights on U-pipe and Coaxial heat exchangers in groundwaterfilled boreholes. KTH Royal Institute of Technology, Energiteknik. PhD Thesis. bttp://mwn.divaportal.org/smash/get/diva2:602905/FULLTEXT01.pdf

Beier, R.A., and M.D. Smith. 2003. Removing Variable Heat Rate Effects from Borehole Tests. ASHRAE Transactions 109(2): 463-474.

Carslaw, H.S. and J.C. Jaeger. 1947. Conduction of Heat in Solids, Claremore Press, Oxford, U.K.

Eklöf, C. and S. Gehlin. 1996. TED - a mobile equipment for thermal response test: testing and evaluation. Department of Environmental Planning and Design. Luleå University of Technology. Master Thesis.

Eurobserv'er. 2015. Heat Pump Barometer. bttps:/ / wnw.eurobserv-er.org/ heat-pump-barometer-2015/

Fossa, M. 2016. Correct design of vertical borehole heat exchanger systems through the improvement of the Ashrae method. Science and Technology for the Built Environment. Accepted for publication.

Fujii, H., H. Okubo, and R. Itoi. 2006. Thermal response tests using optical fiber thermometers. Transactions-Geothermal Resources Council 30: 545-551.

Gehlin, S., G. Hellström, and B. Nordell. 2003. Comparison of four models for thermal response test evaluation. ASHRAE Transactions 109: 131-142.

Gustafsson A-M. 2010. Thermal Response Tests - Influence of convective flow in groundwater filled borehole heat exchangers. Division of Architecture and Infrastructure. Department of Civil, Mining and Environmental Engineering. Luleå University of Technology. PhD Thesis. bttp:/ / ltu.diva-portal.org/smash/get/diva2:990084/FULLTEXT01.pdf

Gustafsson, A-M., and L. Westerlund. 2011. Heat extraction thermal response test in groundwater-filled borehole heat exchanger-Investigation of the borehole thermal resistance. Renewable Energy 36(9): 2388-2394.

Gustafsson, A-M., L. Westerlund, and G. Hellström. 2010. CFD-modelling of natural convection in a groundwater-filled borehole heat exchanger. Applied thermal engineering 30(6): 683-691.

Javed, S., and J.D. Spitler. 2016. Calculation of borehole thermal resistance. In Rees S. "Advances in ground-source heat pump systems". Woodhead Publishing Series in Energy.

Marcotte, D., and P. Pasquier. 2008. On the estimation of thermal resistance in borehole thermal conductivity test. Renewable Energy 33(11): 2407-2415.

Mogensen, P. 1983. Fluid to duct wall heat transfer in duct system heat storages. The International Conference on Subsurface Heat Storage in Theory and Practice. Appendix, Part. II, p. 652-657.

Rolando D. 2013. Modelling of temperature response factors and experimental techniques for borehole heat exchanger design in geothermal heat pump applications. University of Genova, Italy. PhD Thesis.

Signorelli, S., D. Bassetti, D. Pahud and T. Kohl. 2004. 3D numerical modeling of thermal response tests. Geothermics, 31:687-708 
Spitler J, S. Javed, R. Kalskin. 2016. Natural convection in groundwater-filled boreholes used as ground heat exchangers. Applied Energy, 164(15):352-365.

Spitler, J. D., S. Gehlin. 2015. Thermal response testing for ground source heat pump systems - An historical review. Renewable and Sustainable Energy Reviews, 50: 1125-1137.

Witte, H. J. L. 2001. Geothermal response tests with heat extraction and heat injection: examples of application in research and design of geothermal ground heat exchangers. Workshop: Geothermische response tests, EPFL.

Witte, H. J. L., and A. J. Van Gelder. 2006. Geothermal response tests using controlled multi-power level heating and cooling pulses (MPL-HCP): quantifying ground water effects on heat transport around a borehole heat exchanger. Ecostock Conference.

Witte, H.J.L. 2013. Error analysis of thermal response tests. Applied Energy, 109: 302-311.

Witte, Henk JL, G.J. Van Gelder, and J.D. Spitler. 2002. In situ measurement of ground thermal conductivity: a Dutch perspective. ASHRAE Transactions 108: 263-272. 